\title{
Two Cases of Epiphora Following Le Fort I Osteotomy
}

\author{
Jisung Kim, Mi Sook Choi, Dong Wook Lee, and Woo Sub Shim \\ Department of Otorhinolaryngology-Head and Neck Surgery, College of Medicine, Chungbuk National University, Cheongju, Korea
}

\section{Le Fort I 골절단술 후 발생한 유루증 2예}

김지성 · 최미숙 · 이동욱 · 심우섭

충북대학교 의과대학 이비인후과학교실

\author{
Received July 2, 2014 \\ Revised August 24, 2014 \\ Accepted August 29, 2014 \\ Address for correspondence \\ Woo Sub Shim, MD \\ Department of Otorhinolaryngology- \\ Head and Neck Surgery, \\ College of Medicine, \\ Chungbuk National University, \\ 776 1sunhwan-ro, Seowon-gu, \\ Cheongju 362-711, Korea \\ Tel $+82-43-269-6157$ \\ Fax $+82-43-265-6157$ \\ E-mail hwatas@naver.com
}

The lacrimal drainage system begins at the puncta and empties through the valve of Hasner into the inferior meatus. The varieties of the anatomic location, size and morphology of this valve can predispose susceptible individuals to an increased incidence of iatrogenic injury during nasal surgical procedures, thus necessitating a comprehensive understanding of the system. We report two cases of epiphora following two-jaw surgeries for cosmetic purposes. Nasolacrimal duct obstructions were diagnosed, and the symptoms were improved with dacryocystorhinostomies. Korean J Otorhinolaryngol-Head Neck Surg 2014;57(12):861-4

Key Words Le Fort osteotomy · Nasolacrimal duct injury.

\section{Introduction}

Several conditions can cause acquired nasolacrimal duct (NLD) obstruction. These conditions include involutional stenosis of the NLD that presumably results from unidentified infection or autoimmune disease, dacryolith, sinus disease, naso-orbital fractures following trauma, inflammatory diseases, such as Wegener's granulomatosis, neoplasm or iatrogenic injuries during endoscopic paranasal sinus surgery. ${ }^{1-3)}$ The two jaw surgery (TJS) (i.e., maxillary and mandibular osteotomies) has recently become popular for cosmetic purposes and has become an increasing cause of concern regarding NLD obstruction. ${ }^{4)}$ However, there have been no previously reported cases of NLD obstruction associated with TJS.

The NLD can be damaged by excessively high maxillary osteotomies during TJSs, which can result in epiphora. Furthermore, in the absence of direct damage to the NLD or excessive mobilization of the maxillary bone during TJS, ${ }^{4)}$ the soft tissues surrounding the Hasner's valve can cause NLD obstruction. Recently, the authors experienced two cases of NLD obstruction following TJS and report those cases here.

\section{Case}

\section{Case I}

A 22-year-old female presented with epiphora in her right eye. She suffered this symptom over the three months following a TJS that was undertaken for cosmetic purposes in a local plastic surgery clinic. Dacryocystography revealed that the distal portion of the right NLD was completely obstructed and that the right lacrimal sac was dilated (Fig. 1A). Iatrogenic injuries to the bony structures of lacrimal system during the TJS were confirmed by facial bone computerized tomography (CT) (Fig. 1B). Facial bone CT showed a Le Fort I osteotomy in her maxillary bones (Fig. 1C). The osteotomy line was located just above the nasal floor and did not appear to be extremely high; the screws were visualized and found to be of acceptable lengths and placed at ideal depths. Additionally, the 
extent of the mobilization of the maxilla was minimal. The facial bone CT did not revealed any abnormal finding in the bony structures around the NLDs. Based on these findings, injury to the soft tissue around the right NLD during the TJS was suspected as the cause of right epiphora, and a right-side dacryocystorhinostomy was conducted under general anesthesia. During the operation, the patency from the right punctum to the right lacrimal sac was verified with a probe; however, the probe could not be passed down through the right NLD distal to the lacrimal sac. The right lacrimal sac was opened with a drill bur. Her right epiphora was completely resolved after this operation and there was no recurrence at a follow-up of one year.

\section{Case 2}

A 33-year-old male sought medical assistance for a six- month history of epiphora in his right eye. His past medical history indicated that he had undergone a TJS for cosmetic purposes in a local plastic surgery clinic two months prior to the development of his symptom. To confirm the stenosis of the lacrimal drainage system and the site of the obstruction, a dacryocystography was performed (Fig. 2A). Nothing distal to the lacrimal sac was visible with a contrast medium, and the dye backing up during this procedure. A facial bone CT revealed that the patient had undergone a Le Fort I osteotomy in his maxillary bones (Fig. 2B and C). The facial bone CT also revealed that the osteotomy line was located just above the nasal floor and far below the lower margins of the inferior turbinates. The screws that were of acceptable lengths, and the depths of the screws placements seemed appropriate. However, the sagittal views from facial bone $\mathrm{CT}$ revealed that the length of the anterior mobilization of the maxilla was approx-
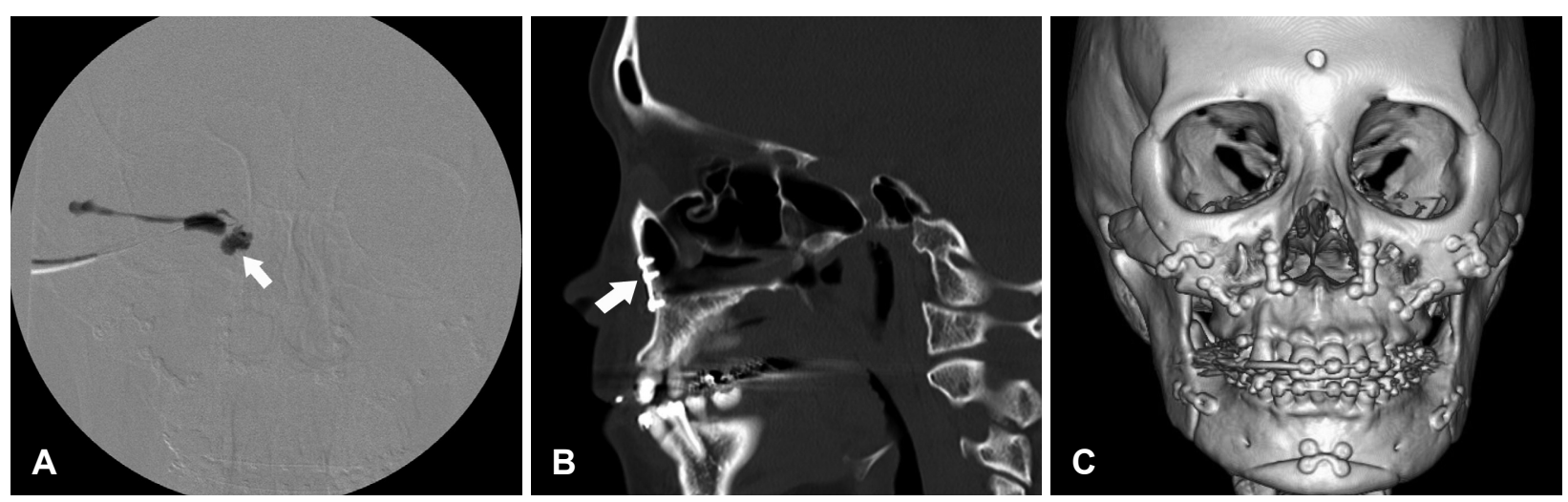

Fig. 1. Preoperative dacryocystographic and computed tomographic findings for case 1. Dacryocystography. No visible passage of the contrast media through the nasolacrimal duct and saccal dilatation (arrow) (A). Facial bone computed tomography. Genioplasty, mandibular and Le Fort I osteotomy status. The anterior advancement of maxilla was insignificant (arrow) (B). Three-dimensional reconstructed facial bone computed tomography (C).
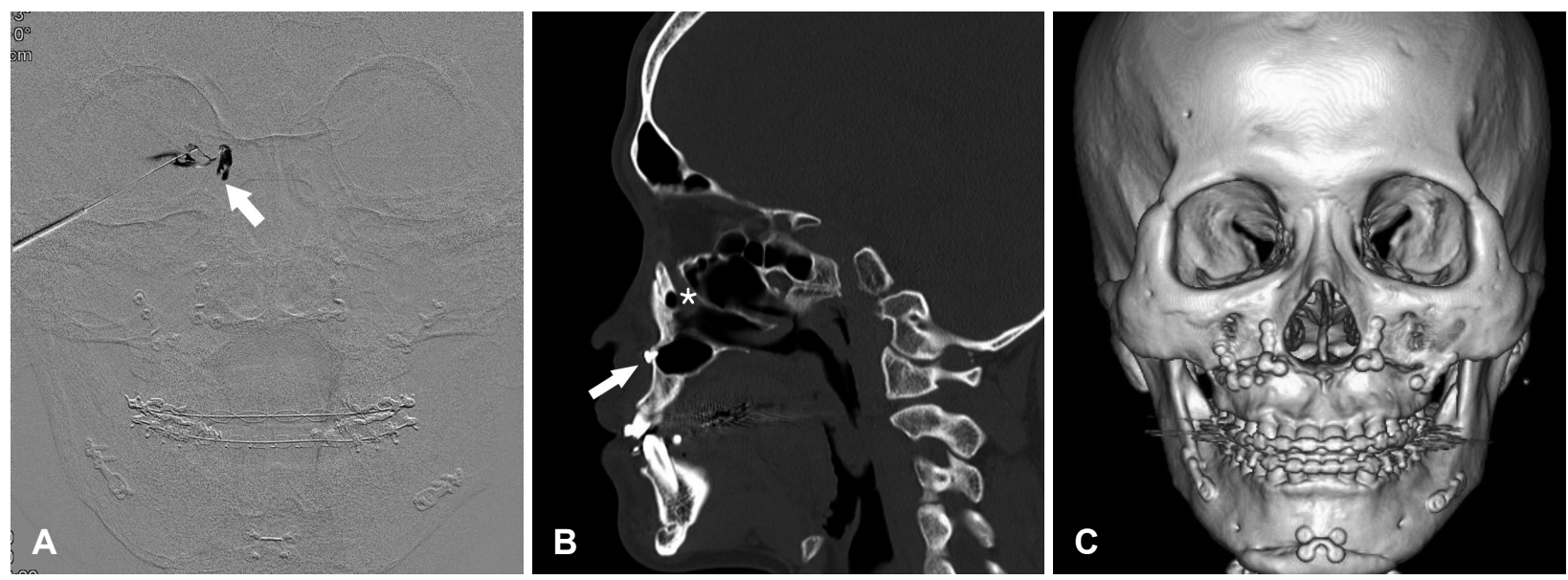

Fig. 2. Preoperative dacryocystographic and computed tomographic findings for case 2. Dacryocystography. No visible passage of the contrast media through the nasolacrimal duct (NLD) (arrow) (A). Facial bone computed tomography. Genioplasty, mandibular and Le Fort I osteotomy status. The anterior advancement of maxilla was significant (arrow) compared to the width of the NLD (asterisk) (B). Three-dimensional reconstructed facial bone computed tomography (C). 
imately $3 \mathrm{~mm}$, which was wider than the $2.5 \mathrm{~mm}$ width of the right NLD. Based on these findings, kinking of the right NLD resulting from an extreme advancement of the maxilla during the TJS was suspected to be the cause of the right epiphora.

Dacryocystorhinostomy was performed under general anesthesia; a twisted sac was observed, and the right lacrimal sac was opened via sac marsupialization. The patient's right epiphora fully recovered immediately after the operation, and a follow-up at 8 months revealed no recurrence.

\section{Discussion}

The nasolacrimal system is divided into proximal and distal segments. The proximal segment is composed of the superior and inferior puncta and canaliculi and the common canaliculus, which is connected to lacrimal sac through the Rosenmueller valve. The distal segment includes the lacrimal sac and the NLD. The upper third of the lacrimal sac is supported within a fossa of the lacrimal bone and surrounded by the periorbita, and the middle third is enveloped by the two limbs of the medial canthal tendon. In contrast, the distal third of the lacrimal sac has no surrounding structures to protect it from injuries and is relatively vulnerable to external trauma. ${ }^{5)}$ The NLD travels in the anterosuperior to posteroinferior direction for 15 to $20 \mathrm{~mm}$ along the lateral nasal wall of the inferior meatus and empties through Hasner's valve into the nasal cavity. Hasner's valve is typically located 11 to $17 \mathrm{~mm}$ above the nasal floor and protected by the inferior turbinate. ${ }^{6)}$ From individual to individual, this valve varies widely in size, morphology and anatomic location, including the distance from the nasal floor, and is particularly susceptible to iatrogenic injuries. ${ }^{7)}$

The majority of post-traumatic NLD obstructions, including iatrogenic cases, result from edematous swelling of the tissues around the NLD, which is reversible, and direct injuries to the NLD are relatively uncommon. These factors explains why the majority of post-traumatic NLD obstructions are resolved with the subsiding of edema fallowing expectant observations. $^{8)}$

The Le Fort I osteotomy is a procedure that is designed to separate the tooth bearing maxillary component from the superior part of the maxilla. The mobilized segment can be moved in every direction, and the procedure is a highly versatile tool for the correction of maxillary deformities. In this procedure, the osteotomy is typically made at the level of the nasal floor parallel to the lower ends of the inferior turbinates at a safe distance from the apices of the teeth, and internal fixation is performed with four miniplates and screws following maxillary repositioning. During this procedure, the distal part of the NLD is susceptible to injury due to its proximity to the osteotomy line and use of the screws. ${ }^{9}$

There are a number of possible mechanisms of permanent NLD injuries following Le Fort I osteotomies. First, Hasner's valve can be damaged by unnecessary mucoperiosteal dissection at the nasal floor and the lateral nasal wall. Second, the distal portion of the NLD can be lacerated during the osteotomy itself in cases in which the osteotomies are made far above the nasal floor and cases in which the Hasner's valves are abnormally low-lying near the lower margins of the inferior turbinates. Another possible mechanism is excessive downward retraction of the tooth-bearing maxillary component to separate it from the superior part of the maxilla after the osteotomy, which can tear the NLD. Additionally, the NLD can be twisted or entangled due to excessive anterior or posterior mobilization of the maxilla during the repositioning of the maxilla. Moreover, excessive inferior movement of the maxilla can lengthen the NLD, and this immoderate force of elongation can cause secondary fibrosis of the NLD. Another possibility is that the osteotomy and the segmental removal of the maxilla followed by the upward movement of the mobilized segment for the correction of the vertical height can impede the realignment of the mucosa around the NLD and cause the NLD to fold or twist.

In case 1, a distal NLD obstruction was verified by dacryocystography, but the facial bone CT did not reveal any abnormal finding in the bony structures around the right NLD. In case 2 , the dacryocystography revealed that the patient had a distal NLD obstruction, and the facial bone CT revealed that the length of anterior mobilization of maxilla was wider than the width of right NLD. Therefore, injuries to soft tissues around the right NLD during the course of the TJS procedure were suspected in case 1, and extreme anterior mobilization of the maxilla during the TJS causing NLD twisting or folding was suspected as the cause of right epiphora in case 2 .

Based on the above cases, we suggest that NLD obstructions can occur following Le Fort I osteotomies. Due to the risk of this complication, thorough preoperative explanations and the acquisition of informed consent are necessary. Additionally, surgeons should be aware of the possibility of injuring the NLD during facial cosmetic surgeries, particularly TJSs, should have a comprehensive knowledge of the lacrimal drainage system and should be cautious not to injure this system, including the 
NLD, during the operation.

\section{REFERENCES}

1) Harris GJ, Fuerste FH. Lacrimal intubation in the primary repair of midfacial fractures. Ophthalmology 1987;94(3):242-7.

2) Osguthorpe JD, Hoang G. Nasolacrimal injuries. Evaluation and management. Otolaryngol Clin North Am 1991;24(1):59-78.

3) Becelli R, Renzi G, Mannino G, Cerulli G, Iannetti G. Posttraumatic obstruction of lacrimal pathways: a retrospective analysis of 58 consecutive naso-orbitoethmoid fractures. J Craniofac Surg 2004; 15(1):29-33.

4) Little C, Mintz S, Ettinger AC. The distal lacrimal ductal system and traumatic epiphora. Int J Oral Maxillofac Surg 1991;20(1):31-5.
5) Dutton JJ, White JJ. Imaging and clinical evaluation of the lacrimal drainage system. In: Cohen AJ, Mercandetti M, Brazzo BG, editors. The Lacrimal System-Diagnosis, Management and Surgery. New York: Springer;2006. p.74-95.

6) Calhoun KH, Rotzler WH, Stiernberg CM. Surgical anatomy of the lateral nasal wall. Otolaryngol Head Neck Surg 1990;102(2):156-60.

7) Lanigan DT, Romanchuk K, Olson CK. Ophthalmic complications associated with orthognathic surgery. J Oral Maxillofac Surg 1993; 51(5):480-94.

8) Shoshani Y, Samet N, Ardekian L, Taicher S. Nasolacrimal duct injury after Le Fort I osteotomy. J Oral Maxillofac Surg 1994;52(4):406-7.

9) Lanigan DT, Guest P. Alternative approaches to pterygomaxillary separation. Int J Oral Maxillofac Surg 1993;22(3):131-8. 